\title{
Fatty Acid Profiling of Polyethylene Glycol Adapted and Un-Adapted Cell Lines of Oryza sativa L.cv. Swat-1 under Temperature Stress
}

\author{
Syed Muhammad Sadiq Shah ${ }^{1 * \#, ~ F a r h a n ~ U l l a h ~}{ }^{2 \#, ~ S a f d a r ~ H u s s a i n ~ S h a h ~}{ }^{3 *}$ \\ ${ }^{1}$ Institute of Crop Science, National Engineering Laboratory for Crop Molecular Breeding, Chinese Academy of Agricultural \\ Sciences, Beijing, China \\ ${ }^{2}$ National Key Laboratory of Crop Genetic Improvement, Huazhong Agricultural University, Wuhan, China \\ ${ }^{3}$ Institute of Biotechnology and Genetic Engineering, University of Agriculture, Peshawar, Pakistan \\ Email: *smsadiqshah@hotmail.com, farhanullah@webmail.hzau.edu.cn, *drsfadar@yahoo.co.in
}

How to cite this paper: Shah, S.M.S., Ullah, F. and Shah, S.H. (2019) Fatty Acid Profiling of Polyethylene Glycol Adapted and Un-Adapted Cell Lines of Oryza sativa L.cv. Swat-1 under Temperature Stress. American Journal of Molecular Biology, 9 , 145-153.

https://doi.org/10.4236/ajmb.2019.94011

Received: January 16, 2019

Accepted: August 4, 2019

Published: August 7, 2019

Copyright $\odot 2019$ by author(s) and Scientific Research Publishing Inc. This work is licensed under the Creative Commons Attribution International License (CC BY 4.0).

http://creativecommons.org/licenses/by/4.0/

\begin{abstract}
Higher plants can adapt to abiotic stress to a certain degree. In this study, the impact of temperature stress on osmotic stress adapted and un-adapted cell lines of rice (Oryza sativa L.cv Swat-1) was observed. For the change in proline content, relative growth rate, saturated and unsaturated fatty acid were evaluated. The cell lines were incrementally adapted to $20 \%$ polyethylene glycol. The adapted lines showed significantly higher growth rate and proline content as compared to the un-adapted cell lines on temperature stress. Among saturated fatty acids palmitic acid (C16:0), stearic acid (C18:0) and myristic acid (C14:0) were the prominent fatty acids detected while among unsaturated fatty acid Oleic acid (C18:1c) and Linoleic acid (C18:2c) were the major fatty acids found. Under low temperature stress the percentage of saturated fatty acids was found to be lower (53\%) in adapted cell line as compared to the un-adapted cell line (63\%) while the percentage of saturation increased (83\%) in adapted line under high temperature stress as compared to un-adapted line (70\%). On the other hand at low temperature stress the percent level of unsaturated fatty acids in the adapted line was higher (48\%) than the un-adapted cell line (37\%). In conclusion, adaptation to one abiotic stress confers co-tolerance to the other abiotic stresses. Fatty acids saturation level could be a crucial factor in the plant ability to tolerate heat and cold stress.
\end{abstract}

\section{Keywords}

Abiotic Stress, Callus Culture, Osmotic Stress, Temperature Stress, Relative Growth Rate, Fatty Acid Profile, Proline Content

\#These authors contributed equally to the paper as first authors. 


\section{Introduction}

Rice (Oryza sativa L.) is one of the most important food crops, widely grown and accounts for providing food for half the world's population [1]. In Asia, it is the most important staple food where more than $90 \%$ of the world's rice is grown and consumed. Drought and salinity are two major abiotic stresses that severely constrain plant growth and productivity [2]. Rice is considered to be highly sensitive to salt stress [3]. Saline environments generally cause changes in plant lipid metabolism [4].

Drought is considered to be the main cause of crop losses worldwide, reducing average yields for most major crop plants by more than 50\% [5]. During the drought the dehydration process is characterized by fundamental changes in water relations, membrane structure, biochemical and physiological processes [6].

Proline accumulates in many plants as a response to osmotic stress [7]. This response is thought to be the key in osmotic stress tolerance [8]. Plasma membrane is the first among the cell parts to contact abiotic stresses and therefore, play a vital role in triggering primary responses by regulating the permeability of the membrane [9]. Change in the sterols and fatty acids levels in the cell membrane is one of the adaptation mechanisms adapted by plants to cope with abiotic stresses [10]. The present study was undertaken to develop cell lines tolerant to osmotic stress by adapting them to osmotic/drought stress (20\% PEG) and to investigate the change in both lines under temperature stresses.

\section{Materials and Methods}

The Research was conducted at the Institute of Biotechnology and Genetic Engineering (IBGE) the University of Agriculture Peshawar and Pakistan Council for Scientific and Industrial Research (PCSIR) Peshawar.

\subsection{Growth Media for Suspension Culture}

The basal Murashige and Skoog (MS) medium was used for multiplication and selection of lines tolerant to PEG [11]. Cell lines were incrementally adapted to osmotic stress by using polyethylene glycol (up to 20\% PEG) following Shah et al. (2012) [12].

\subsection{Media/Equipment Sterilization}

The media was sterilized by autoclaving (at pressure 15 p.s.i and temperature $121^{\circ} \mathrm{C}$ ) for 20 minutes. Other equipments (scalpel, forceps, Pasteur pipettes, spatulas and glassware) were wrapped in aluminum foil and sterilized by autoclaving.

\subsection{Adaptation of Cell Lines to PEG}

The cell line from the rice was adapted to 20\% PEG by a multistep adaptation procedure following Shah et al. (2012) [13]. Cell lines were subjected to an incremental increase in PEG concentration. Initially calli was inoculated in suspension medium containing 5\% PEG. After 2 cultures (10 days each), flasks with 
maximum growth were sub-cultured on medium containing $10 \%$ PEG. In similar way, stable lines were sub-cultured on medium with higher stress until a stable line was obtained on medium containing $20 \%$ PEG.

\subsection{Temperature Stress}

For heat and cold stress, the cell lines were subjected to $36^{\circ} \mathrm{C}$ and $18^{\circ} \mathrm{C}$, respectively for two weeks.

\subsection{Determination of Proline Content}

Proline was extracted by the method of Singh et al. (1973) [14] and determined by the method of Bates et al. (1973) [15].

\subsection{Fatty Acid Extraction}

Total cellular fatty acid content from rice cell lines was extracted by following the method of Bligh and Dyer (1959) [16]. The fatty acid analysis was performed using gas chromatography-mass spectrometry (GC-MS).

\subsection{Gas Chromatography/Mass Spectrometry of Fatty Acid Methyl Esters}

The fatty acid methyl esters (FAMEs) were determined by gas chromatography on a GCMS-QP2010 plus, equipped with an electron ionization (EI) detector. Chromatography was performed by using a TRB-FFAP (free fatty acid phase) column ( $30 \mathrm{~m} \times 0.32 \mathrm{~m} \times 0.25 \mu \mathrm{M}$ diameter). One microliter of the sample was injected with a 1:50 split ratio. The temperature of injection was $240^{\circ} \mathrm{C}$, the ion source was kept at $250^{\circ} \mathrm{C}$ and the interface was kept at $240^{\circ} \mathrm{C}$. Oven temperature program was on hold for $1 \mathrm{~min}$ at $50^{\circ} \mathrm{C}$, followed by a $15^{\circ} \mathrm{C} \cdot \mathrm{min}^{-1}$ rise to $150^{\circ} \mathrm{C}$, $5 \mathrm{~min}$ at $175^{\circ} \mathrm{C}$, and a final $5 \mathrm{~min}$ at $220^{\circ} \mathrm{C}$ prior to the next injection. Helium was used as the carrier gas. Compounds were identified by comparison of retention time with external standard and further confirmed by similarity search using mass spectral libraries. NIST (National Institute of Standards and Technology) database was used as external standard.

\subsection{Measurement of Growth}

The growth of calli was measured following Shah et al. (1990) [17]. A mesh scoop was used to add a similar amount of calli to flasks containing $80 \mathrm{ml}$ suspension culture medium. The average amount of calli in one scoop was measured and the initial fresh weight was obtained. The cultures were incubated in dark. After 2 weeks the media was discarded and the total calli was weighted to obtain final fresh weight.

\section{Results and Discussion}

In the present study, an attempt was made to examine the response of osmotically adapted (PEG) and un-adapted (control) lines of Oryza sativa L. cv. Swat-1 to heat and cold stress with respect to growth, proline accumulation, and fatty 
acid profiles.

\subsection{Effect of Temperature Stress on Relative Growth Rate}

Our results show that control cell lines showed a slow growth rate at lower and higher temperatures tested, in contrast, adapted cell lines maintained the same growth rate at the tested temperatures compared to permissible temperature $\left(28^{\circ} \mathrm{C}\right)$ (Figure 1). This indicates that cell line adapted to osmotic stress show the phenomenon of co-adaptation to heat and cold stress.

\subsection{Effect of Temperature Stress on Proline Content}

An increase in the level of proline was observed in PEG adapted line on optimal temperature and the levels were maintained during temperature stress conditions. However, the proline levels in un-adapted line seem to be unaffected with low and high temperature. This indicates that a higher accumulation of proline in adapted lines is a response to osmotic stress rather than temperature stress. Higher proline levels seem to be associated with higher growth rates of adapted cell lines whereas low proline associated with poor growth rates of un-adapted cell lines (Figure 2).

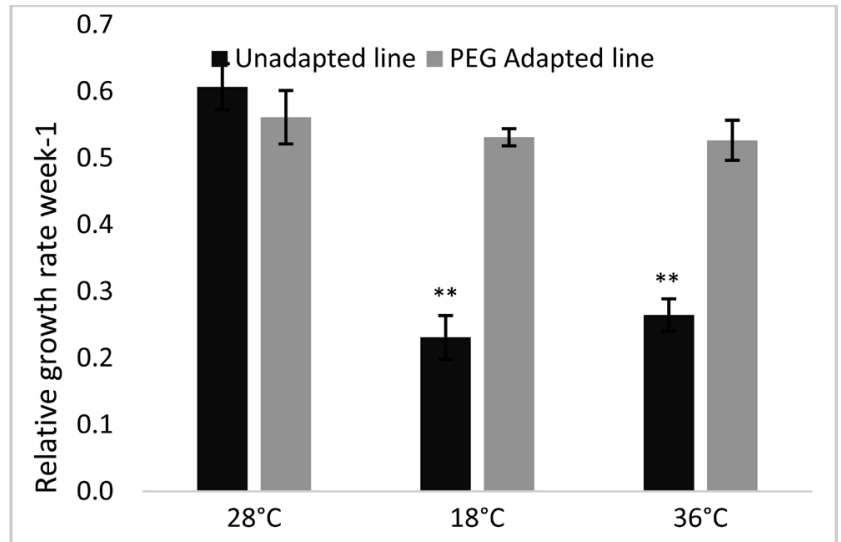

Figure 1. Effect of temperature stress on RGR of adapted and un-adapted cell lines. The data presented are means of 5 replicate \pm SE. ${ }^{*}$ Represent highly significant decrease in relative growth rate (RGR) of un-adapted cell lines (control).

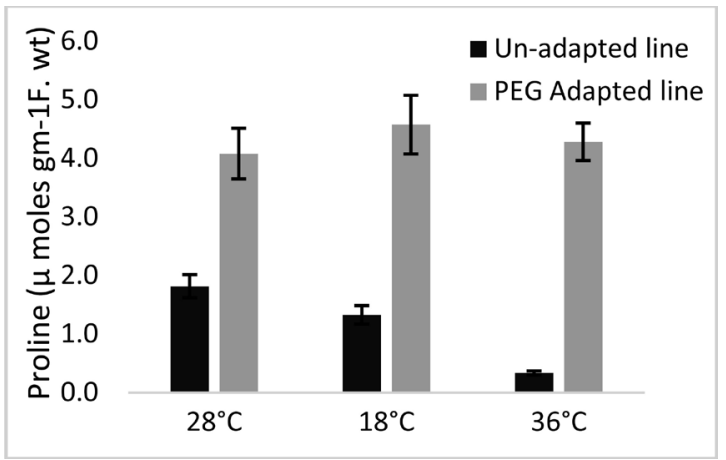

Figure 2. Effect of temperature stress on proline content. The data presented are means of 5 replicate \pm SE. 
These results are in agreement with the previous results of Shah et al. (2012); Wahid and Close (2007) [12] [18]; who reported that accumulation of proline in the cell, may buffer cellular redox potential under cold, heat and other environmental stresses.

\subsection{Fatty Acid Profile of Adapted and Un-Adapted Cell Lines}

A total of fifteen fatty acids were detected in adapted and un-adapted cell lines which were classified as saturated and unsaturated fatty acids as shown in the Table S1.

Among these 10 were saturated fatty acids, all these were not detected in both lines. The common saturated fatty acids among both cell lines were Myristic acid (C14:0), Palmitic acid (C16:0), Stearic acid (C18:0) while the common unsaturated fatty acid found were Oleic acid (C18:1c) and Linoleic acid (C18:2c).

Palmitic acid was the most abundant fatty acid detected in all cell lines, followed by Oleic acid, linoleic acid, stearic acid and myristic (Table 1).

\subsection{Effect of Temperature Stress on Fatty Acid Profile}

In our experiments, the un-adapted line showed higher level of saturated fatty acid as compared to the adapted cell line under optimal conditions. Under cold stress a decrease was observed in both lines while under heat stress the percent level was higher in adapted cell lines than the un-adapted cell line (Figure 3).

Furthermore, our data reveals that the level of fatty acid unsaturation increased at low temperature while at high temperature the level decreased as shown in Figure 4.

It is reported that plasma membrane having a higher proportion of unsaturated

Table 1. Range of most prominent fatty acid detected in control and PEG cell lines under temperature stress using gas chromatography-mass spectrometry (GC-MS).

\begin{tabular}{cccccc}
\hline & Palmitic acid & Oleic acid & linoleic acid & stearic acid & myristic acid \\
\hline Control line & $49 \%$ to $56 \%$ & $14 \%$ to $21 \%$ & $11 \%$ to $19 \%$ & $11 \%$ to $16 \%$ & $1.8 \%$ to $2.9 \%$ \\
PEG line & $40 \%$ to $59 \%$ & $12 \%$ to $28 \%$ & $4 \%$ to $20 \%$ & $10 \%$ to $19 \%$ & $2.8 \%$ to $5.2 \%$ \\
\hline
\end{tabular}

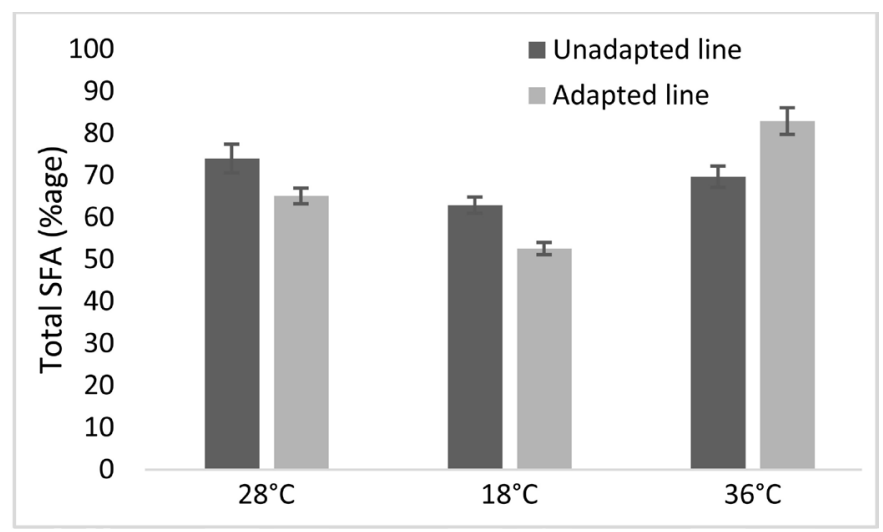

Figure 3. Total saturated fatty acid profile in rice lines under temperature stress. 


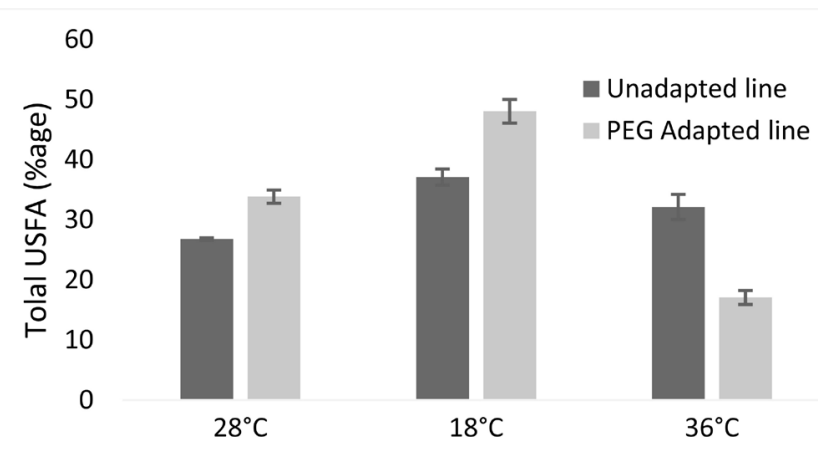

Figure 4. Profile of total unsaturated fatty acids in rice cell lines under temperature stress.

fatty acids is usually tolerant to low temperature stress while a higher proportion of saturated fatty acids renders tolerance to higher temperature stress [9] [19]. Furthermore, the degree of lipid unsaturation is related to cold tolerance due to its effect on PM stability [20].

Plant basic physiological response to drought stress overlaps temperature, as well as salt stress; that ultimately leads to dehydration in growing plants [5]. Thermal adaptation is related to biochemical and physiological responses of the plant which are mainly caused by changes in lipidic fluidity of membranes [21]. Plants respond to different abiotic stresses (drought, heat and salinity) by the changes in the degree of un-saturation of fatty acids [22].

It is interesting to note that PEG adapted cell lines have shown differential response to low and high temperature. Under low temperature it accumulated a high concentration of unsaturated fatty acids while under high temperature it had a high percentage of saturated fatty acids as compared to the un-adapted cell line. Similar results have been reported by [23] and [24] that increase in temperature increase the level of saturated fatty acids in membrane lipids and enhance the heat stability of cell membrane. While with decrease in temperature the level of saturated fatty acid decreased. This suggests that the cold temperature activates fatty acid desaturation and the saturated fatty acids were converted to unsaturated fatty acids to stabilize PM under cold environment [25]. An increase in total saturated and unsaturated fatty acids under high and low temperatures respectively, have obviously affected the fluidity of the plasma membrane [26].

\section{Conclusion}

Our research findings suggest that adaptation to osmotic stress may result in adjustments due to increased sensitivity or due to enhanced signaling system of the cell that makes cells capable to respond to changing environment effectively than the cells of un-adapted cell lines. Based on the results of the present study it is recommended that a large number of plants need to be regenerated for studying this cross adaptation mechanism at the whole plant level.

\section{Acknowledgements}

Authors are highly thankful to the research supervisor Dr. Safdar Hussain Shah 
(Director, Institute of Biotechnology and Genetic Engineering) for his guidance and kind support. We are very thankful to Dr. Ali Anwar for critical reading and comments on the manuscript.

\section{Conflicts of Interest}

The authors declare no conflicts of interest regarding the publication of this paper.

\section{References}

[1] Zeng, L.-H. and Shannon, M.C. (2000) Salinity Effects on Seedling Growth and Yield Components of Rice. Crop Science, 40, 996-1003. https://doi.org/10.2135/cropsci2000.404996x

[2] Boyer, J.S. (1982) Plant Productivity and Environment. Science, 218, 443-448. https://doi.org/10.1126/science.218.4571.443

[3] Flowers, T.J. and Yeo, A.R. (1995) Breeding for Salinity Resistance in Crop Plants: Where Next? Functional Plant Biology, 22, 875-884. https://doi.org/10.1071/PP9950875

[4] Ashraf, M. and Harris, P.J.C. (2004) Potential Biochemical Indicators of Salinity Tolerance in Plants. Plant Science, 166, 3-16. https://doi.org/10.1016/j.plantsci.2003.10.024

[5] Wang, W.-X., Vinocur, B. and Altman, A.J.P. (2003) Plant Responses to Drought, Salinity and Extreme Temperatures: towards Genetic Engineering for Stress Tolerance. Planta, 218, 1-14. https://doi.org/10.1007/s00425-003-1105-5

[6] Yardanov, I., Velikova, V. and Tsonev, T. (2003) Plant Responses to Drought and Stress Tolerance. Bulgarian Journal of Plant Physiology, Special Issue 2003, 187-206.

[7] Seki, M., Umezawa, T., Urano, K. and Shinozaki, K. (2007) Regulatory Metabolic Networks in Drought Stress Responses. Current Opinion in Plant Biology, 10, 296-302. https://doi.org/10.1016/j.pbi.2007.04.014

[8] Nayyar, H. and Walia, D.P. (2003) Water Stress Induced Proline Accumulation in Contrasting Wheat Genotypes as Affected by Calcium and Abscisic Acid. Biologia Plantarum, 46, 275-279. https://doi.org/10.1023/A:1022867030790

[9] Mahajan, S. and Tuteja, N. (2005) Cold, Salinity and Drought Stresses: An Overview. Archives of Biochemistry and Biophysics, 444, 139-158. https://doi.org/10.1016/j.abb.2005.10.018

[10] Elkahoui, S., Smaoui, A., Zarrouk, M., Ghrir, R. and Limam, F.J.P. (2004) Salt-Induced Lipid Changes in Catharanthus roseus Cultured Cell Suspensions. Phytochemistry, 65, 1911-1917. https://doi.org/10.1016/j.phytochem.2004.06.021

[11] Murashige, T. and Skoog, F. (1962) A Revised Medium for Rapid Growth and Bio Assays with Tobacco Tissue Cultures. Physiologia Plantarum, 15, 473-497. https://doi.org/10.1111/j.1399-3054.1962.tb08052.x

[12] Shah, A.H., Shah, S.H., Ahmad, H., Swati, Z.A., Abbasi, F.M., Farhatullah, and Shah, A.H. (2012) Adaptation to Polyethylene Stress Maintains Totipotency of Cell Lines of Oryza sativa L. cv. Swat-1 for a Longer Period. Pakistan Journal of Botany, 44, 313-316.

[13] Shah, A.H., Shah, S.H., Ahmad, H., Swati, Z.A., Afzal, M., Aiman, U. and Khalid, Q. (2012) The Phenomenon of Cross Tolerance in Osmotically and Ionically Adapted Rice (Oryza sativa L.) Cell lines. African Journal of Biotechnology, 11, 713-717. 
[14] Singh, T., Aspinall, D., Paleg, L. and Boggess, S. (1973) Stress Metabolism II. Changes in Proline Concentration in Excised Plant Tissues. Australian Journal of Biological Sciences, 26, 57-64. https://doi.org/10.1071/BI9730057

[15] Bates, L.S., Waldren, R.P. and Teare, I.J.P. (1973) Rapid Determination of Free Proline for Water-Stress Studies. Plant and Soil, 39, 205-207.

https://doi.org/10.1007/BF00018060

[16] Bligh, E.G. and Dyer, W.J. (1959) A Rapid Method of Total Lipid Extraction and Purification. Canadian Journal of Biochemistry and Physiology, 37, 911-917. https://doi.org/10.1139/o59-099

[17] Shah, S., Wainwright, S. and Merrett, M.J. (1990) The Interaction of Sodium and Calcium Chlorides and Light on Growth, Potassium Nutrition, and Proline Accumulation in Callus Cultures of Medicago sativa L. New Phytologist, 116, 37-45. https://doi.org/10.1111/j.1469-8137.1990.tb00508.x

[18] Wahid, A. and Close, T.J. (2007) Expression of Dehydrins under Heat Stress and Their Relationship with Water Relations of Sugarcane Leaves. Biologia Plantarum, 51, 104-109. https://doi.org/10.1007/s10535-007-0021-0

[19] Murakami, Y., Tsuyama, M., Kobayashi, Y., Kodama, H. and Iba, K. (2000) Trienoic Fatty Acids and Plant Tolerance of High Temperature. Science, 287, 476-479. https://doi.org/10.1126/science.287.5452.476

[20] da Cruz, R.P., Golombieski, J.I., Bazana, M.T., Cabreira, C., Silveira, T.F. and da Silva, L.P. (2010) Alterations in Fatty Acid Composition Due to Cold Exposure at the Vegetative Stage in Rice. Brazilian Society of Plant Physiology, 22, 199-207. https://doi.org/10.1590/S1677-04202010000300007

[21] Hur, J.-H., Jung, K.-H., Lee, C.-H. and An, G. (2004) Stress-Inducible OsP5CS2 Gene Is Essential for Salt and Cold Tolerance in Rice. Plant Science, 167, 417-426. https://doi.org/10.1016/j.plantsci.2004.04.009

[22] Zhang, M., Barg, R., Yin, M., Gueta-Dahan, Y., Leikin-Frenkel, A., Salts, Y., Shabtai, S. and Ben-Hayyim, G. (2005) Modulated Fatty Acid Desaturation via Overexpression of Two Distinct $\omega-3$ Desaturases Differentially Alters Tolerance to Various Abiotic Stresses in Transgenic Tobacco Cells and Plants. The Plant Journal, 44, 361-371. https://doi.org/10.1111/j.1365-313X.2005.02536.x

[23] Pearcy, R.W. (1978) Effect of Growth Temperature on the Fatty Acid Composition of the Leaf Lipids in Atriplex lentiformis (Torr.) Wats. Plant Physiology, 61, 484-486. https://doi.org/10.1104/pp.61.4.484

[24] Raison, J.K., Roberts, J.K. and Berry, J.A. (1982) Correlations between the Thermal Stability of Chloroplast (Thylakoid) Membranes and the Composition and Fluidity of Their Polar Lipids upon Acclimation of the Higher Plant, Nerium oleander, to Growth Temperature. Biochimica et Biophysica Acta (BBA)-Biomembranes, 688, 218-228. https://doi.org/10.1016/0005-2736(82)90597-1

[25] Cossins, A.R. (1994) Temperature Adaptation of Biological Membranes.

[26] Wu, J.-L., Seliskar, D.M. and Gallagher, J.L. (1998) Stress Tolerance in the Marsh Plant Spartina patens. Impact of $\mathrm{NaCl}$ on Growth and Root Plasma Membrane Lipid Composition. Physiologia Plantarum, 102, 307-317.

https://doi.org/10.1034/j.1399-3054.1998.1020219.x 


\section{Supplementary Materials}

Table S1. Most prominent fatty acids detected in PEG adapted and un-adapted cell lines of rice O. sativa L.cv. Swat-1.

\begin{tabular}{cccc}
\hline S. no & Fatty Acid & Name & SFA/USFA \\
\hline 1 & C12:0 & Lauric acid & $\mathrm{S}$ \\
2 & C13:0 & Tridecanoic acid & $\mathrm{S}$ \\
3 & C14:0 & Myristic acid & $\mathrm{S}$ \\
4 & $\mathrm{C} 15: 0$ & Pentadecanoic acid & $\mathrm{S}$ \\
5 & $\mathrm{C} 16: 0$ & Palmitic acid & $\mathrm{S}$ \\
6 & $\mathrm{C} 17: 0$ & Margaric acid & $\mathrm{S}$ \\
7 & $\mathrm{C} 18: 0$ & Stearic acid & $\mathrm{S}$ \\
8 & $\mathrm{C} 18: 1 \mathrm{c}$ & Oleic acid & $\mathrm{U}$ \\
9 & $\mathrm{C} 18: 1 \mathrm{n} 9 \mathrm{~T}$ & Elaidic acid & $\mathrm{U}$ \\
10 & $\mathrm{C} 18: 2 \mathrm{c}$ & Linoleic acid & $\mathrm{U}$ \\
11 & $\mathrm{C} 18: 3 \mathrm{n} 3$ & Linolenic acid & $\mathrm{U}$ \\
12 & $\mathrm{C} 20: 0$ & Arachidic acid & $\mathrm{S}$ \\
13 & $\mathrm{C} 22: 0$ & Behenic acid & $\mathrm{S}$ \\
14 & $\mathrm{C} 24: 0$ & Tetracosanoic acid & $\mathrm{S}$ \\
15 & $\mathrm{C} 24: 1$ & Tetracosenoic acid & $\mathrm{U}$ \\
\hline
\end{tabular}

"S" denotes saturated and "U" denotes unsaturated fatty acids. 